\title{
Magnetic and Porous Nanospheres from Ultrasonic Spray Pyrolysis
}

\section{Won Hyuk Suh and Kenneth S. Suslick*}

School of Chemical Sciences, University of Illinois at Urbana-Champaign, $600 \mathrm{~S}$. Mathews Avenue, Urbana, Illinois

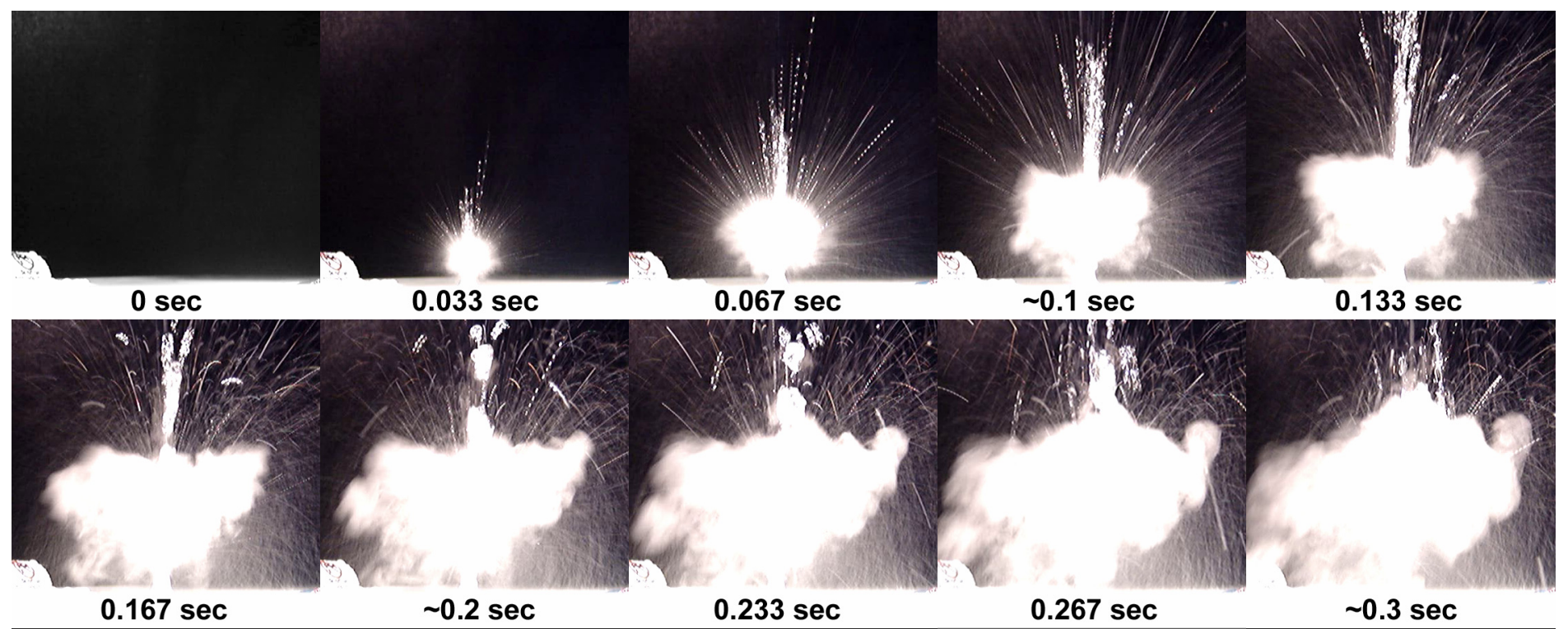

Supporting Information Figure 1. Video frame captures of the ultrasonic fountain as a function of time with water as solvent. The mist generated from $1.7 \mathrm{MHz}$ ultrasound stays consistent after $\sim 0.2 \mathrm{~s}$. SONY DSC-F828 digital camera. The scale shown in each photograph is $\sim 15 \times 15 \mathrm{~cm}$.
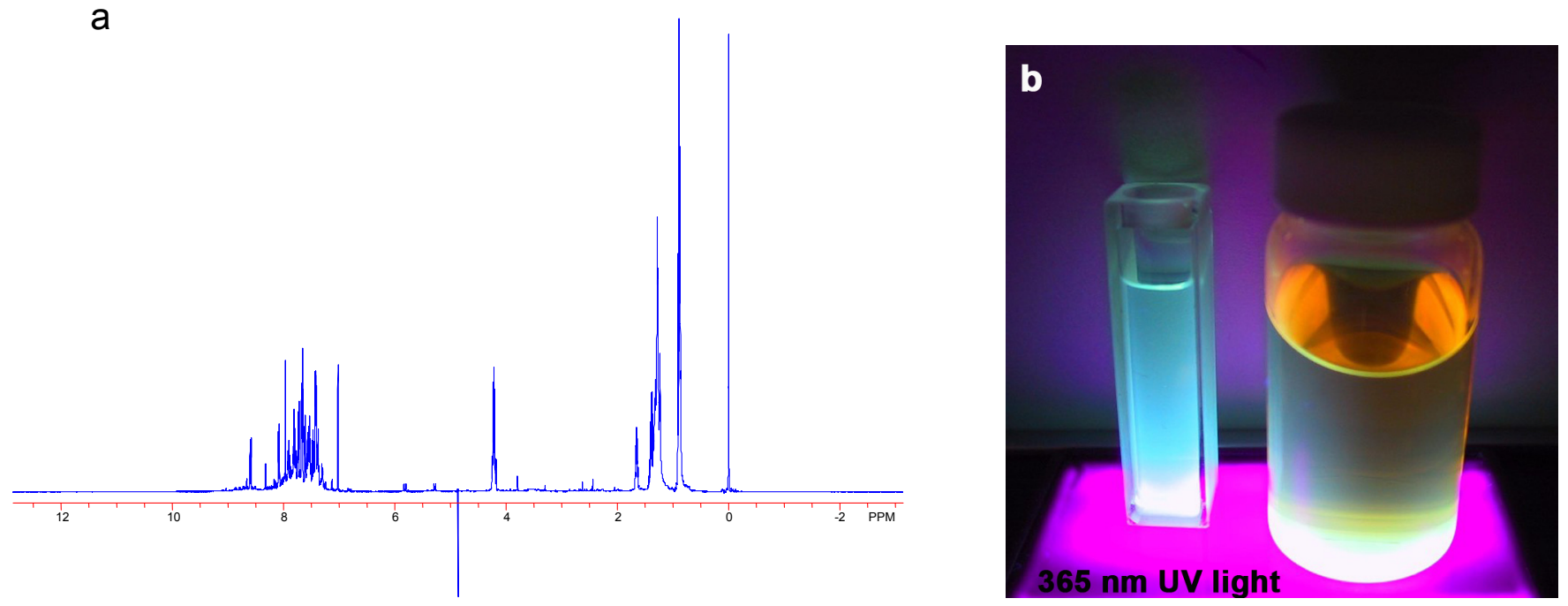

Supporting Information Figure 2. (a) 1H-NMR spectra of organic product from pyrolysis of the organic poylmer. (b) This orange tar is luminescent as shown. The polyphenyl product is only soluble in organic solvents (e.g., toluene and chloroform). 
a

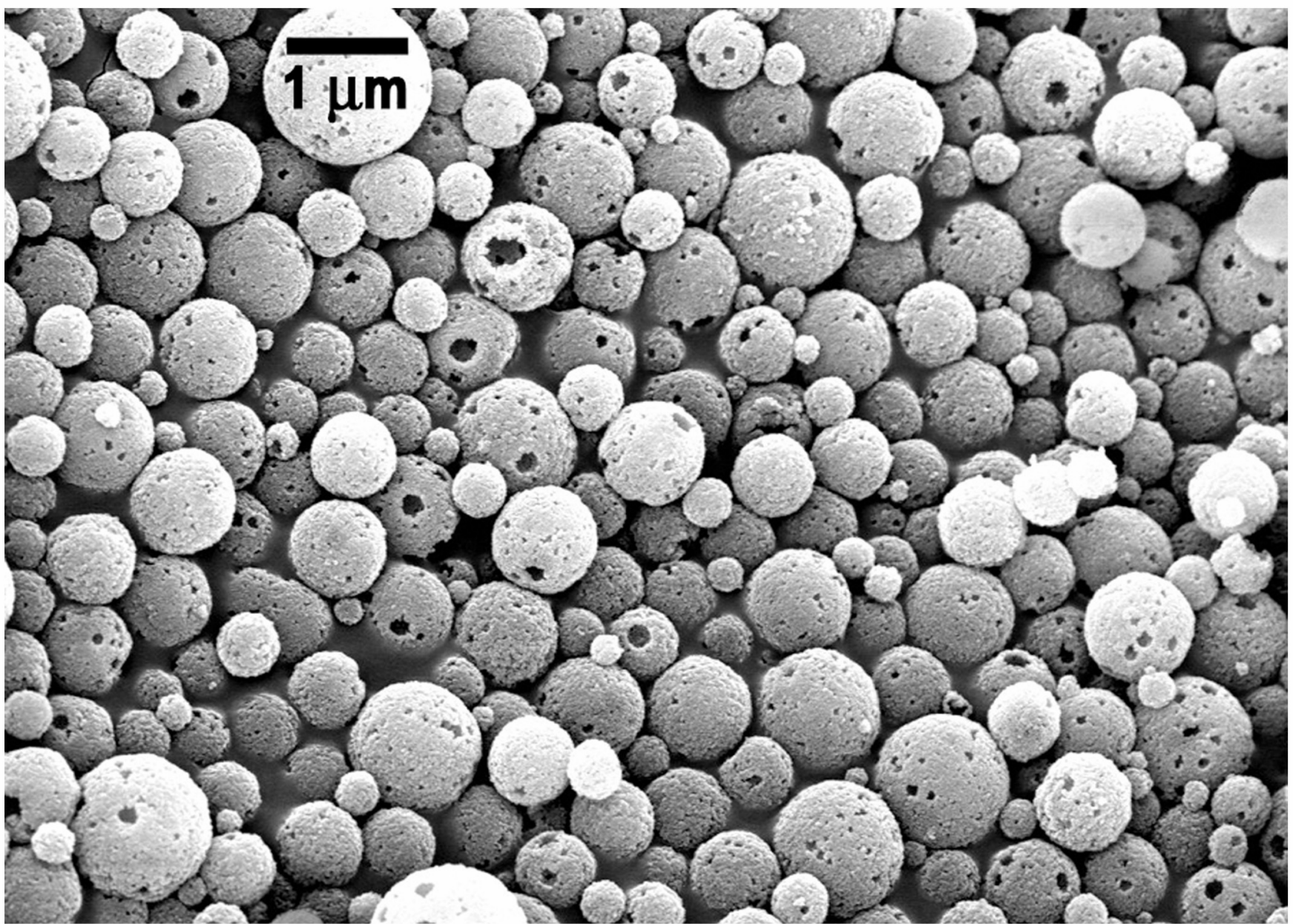

b

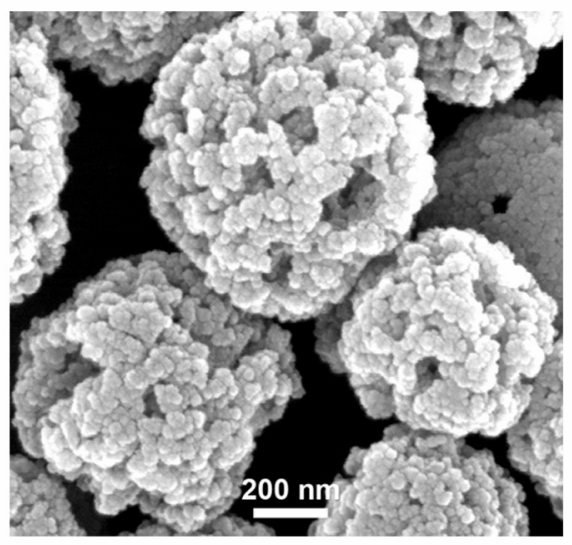

C

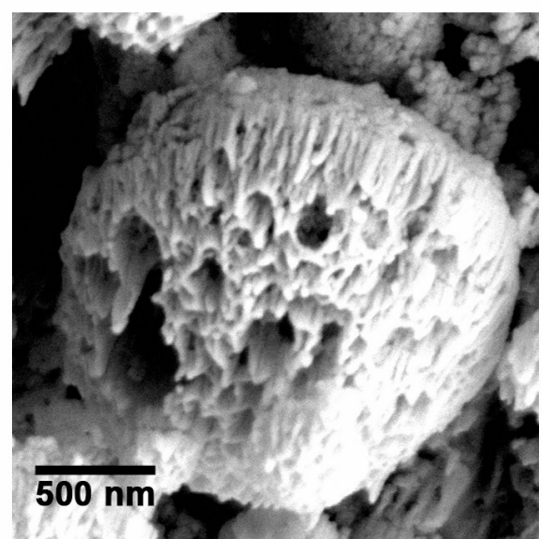

d

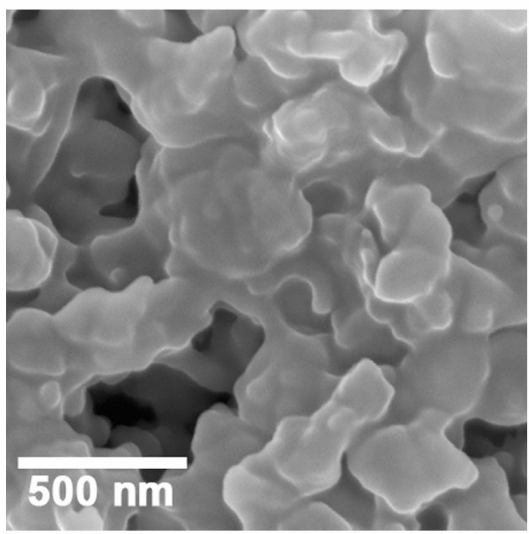

Supporting Information Figure 3. SEM images (a) 3:1 organic monomer to silica low magnification. (b) Monomer:silica=10:1. (c) Inner worm-like structure of b. (d) Monomer:silica=30:1, spherical morphology is lost. 


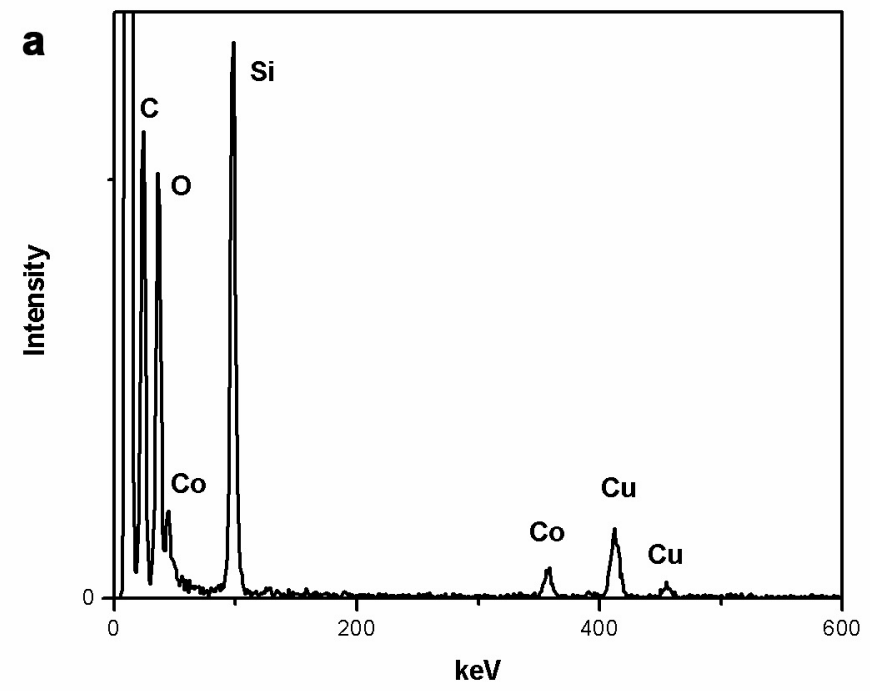

b
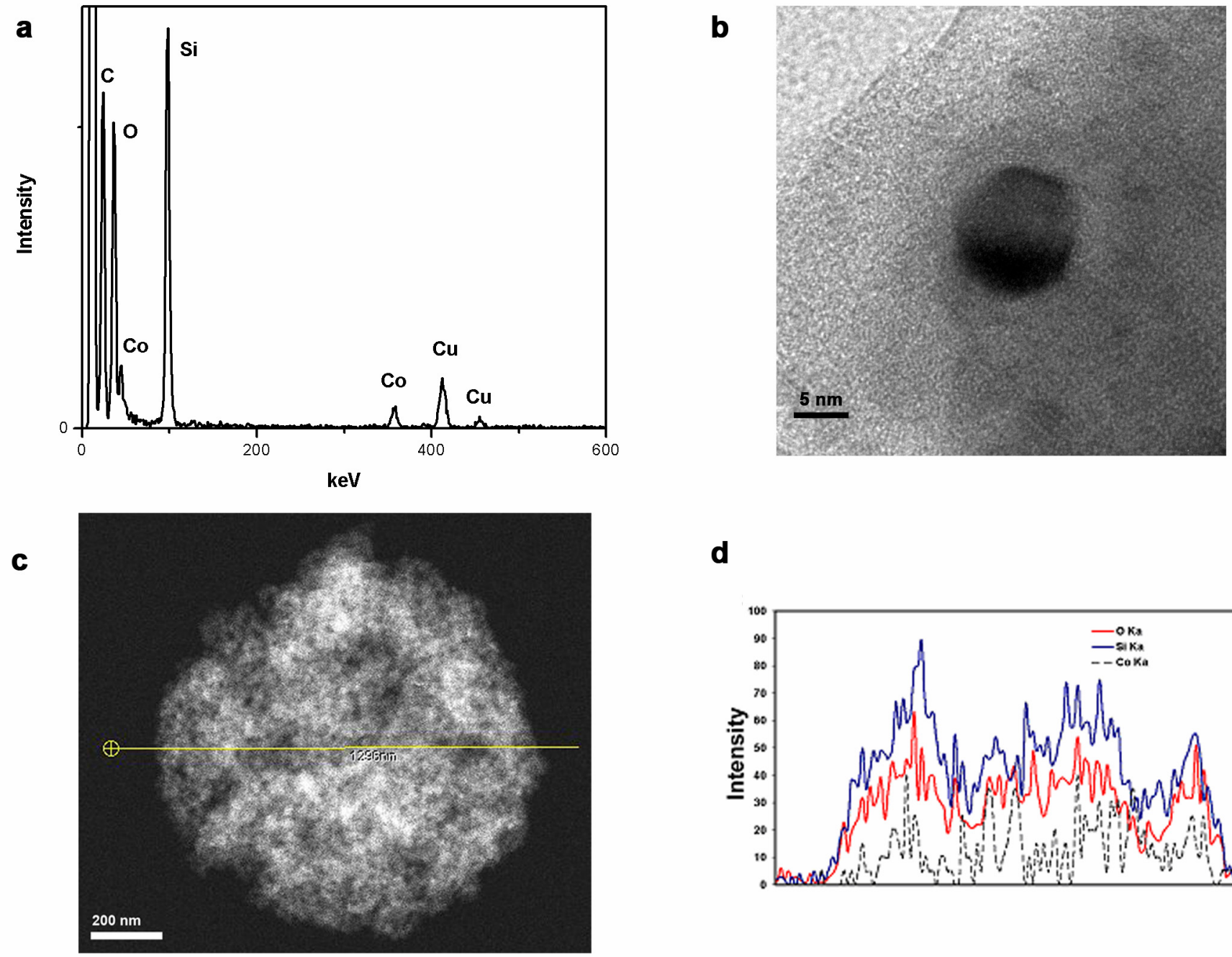

d

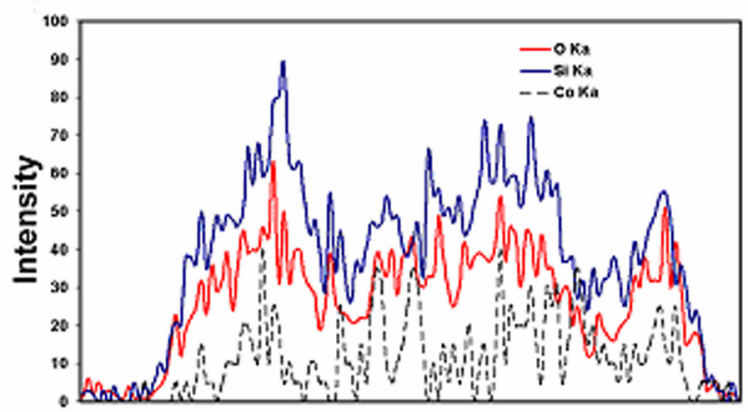

Supporting Information Figure 4. STEM Energy Dispersive Spectral (EDS) Analysis of cobalt doped porous silica prepared from 1:10 silica to organic monomer. JEOL 2010(F) STEM instrument. (a) Spot elemental analysis shows the presence of $\mathrm{Si}, \mathrm{O}$, and $\mathrm{Co}$. The $\mathrm{Cu}$ signal is from the STEM sample holder grid. (b) High magnification TEM of a cobalt nanoparticle in the silica. (c) STEM image of a porous silica; the yellow line indicates the line scan analysis placement. (d) Line scan analysis shows the porous nature of the USP nanospheres. The individual signal intensities of $\mathrm{Si} \mathrm{K}_{\mathrm{a}}$ and $\mathrm{O} \mathrm{K}$ are higher than Co $\mathrm{K}_{\mathrm{a}}$, so the Co $\mathrm{K}_{\mathrm{a}}$ has been scaled by a factor of five. 

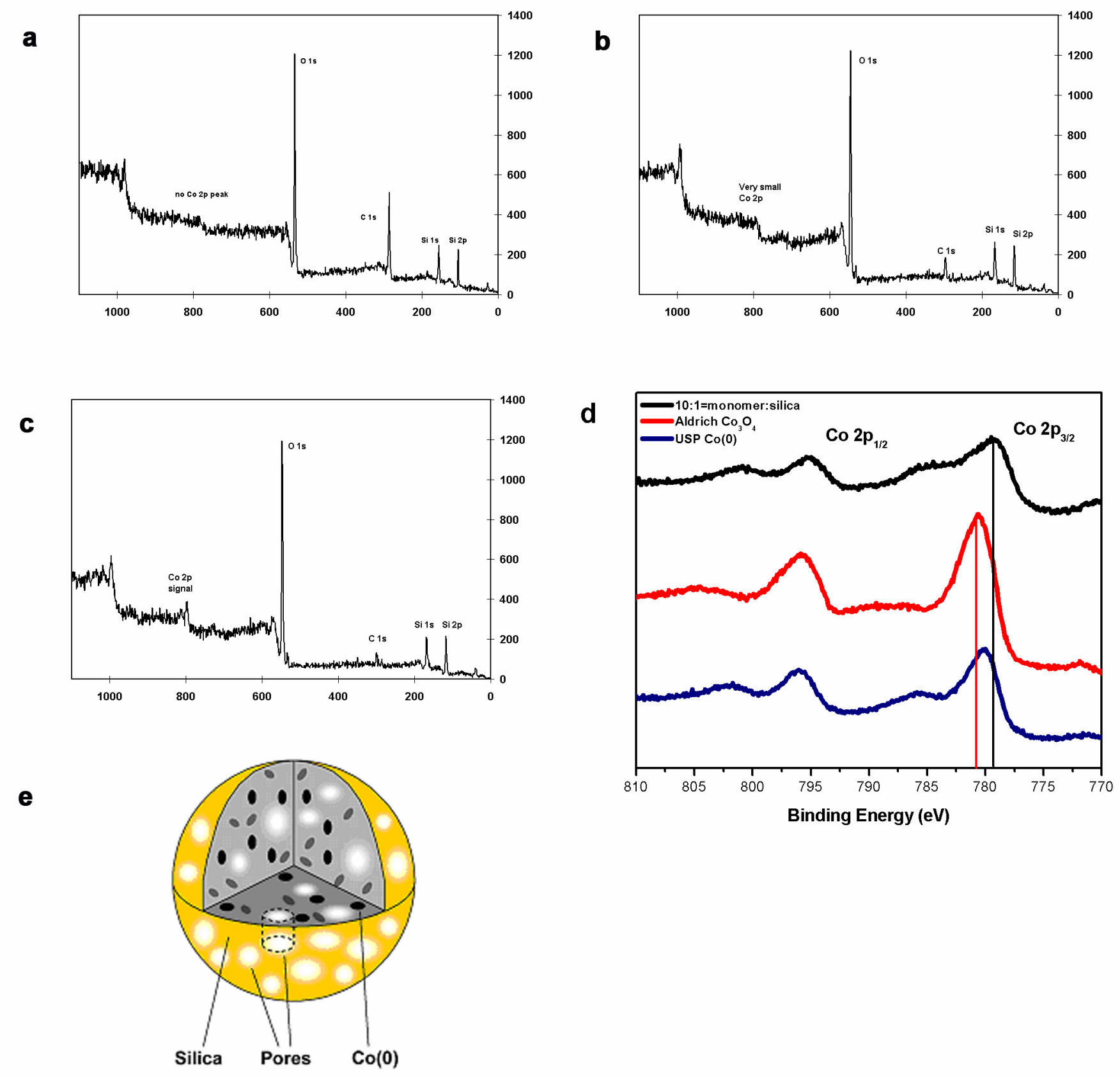

Supporting Information Figure 5. (a) XPS data of cobalt doped porous silica prepared from 1:10 silica to organic monomer. O 1s, Si $2 \mathrm{~s}$, Si $2 p$ signals are present, but no Co $2 p$ signals are observed in the XPS. Since XPS is surface sensitive with a penetration depth of $\sim 4 \mathrm{~nm}$, this means that the $\mathrm{Co}(0)$ nanoparticles produced are embedded in the silica matrix and not on the surface. (b) Depth profiling XPS data. Sputtered with Ar approx. $12 \mathrm{~nm}$. (c) Depth profiling XPS data. Sputtered with $\mathrm{Ar}$ approx. $60 \mathrm{~nm}$. (d) XPS Co $2 p$ data comparison of 1:10=silica:monomer sample (779.4 eV), Aldrich $\mathrm{Co}_{3} \mathrm{O}_{4}(780.6 \mathrm{eV})$, and USP synthesized metallic cobalt $(780.1 \mathrm{eV})$. Prepared USP spheres contain metallic cobalt species. The peaks are consistent with reported data in the literature. ${ }^{1}$ (e) A schematic of the internal morphology of the nanospheres is provided that is consistent with the combination of the TEM, SEM, and EDS analyses.

1 (a) Yang, H.T.; Su, Y. K.; Shen, C. M.; Yang, T. Z.; Gao, H. J. Surf. Interfac. Anal. 2004, 36, 155-160. (b) Manivannan, A.; Seehra, M. S.; Majumder, S. B.; Katiyar, R. S. Appl. Phys. Lett. 2003, 83, 111-113. (c) Watts, J. F.; Wolstenholme, J. An Introduction to Surface Analysis by XPS and AES; Wiley: London, 2003. 

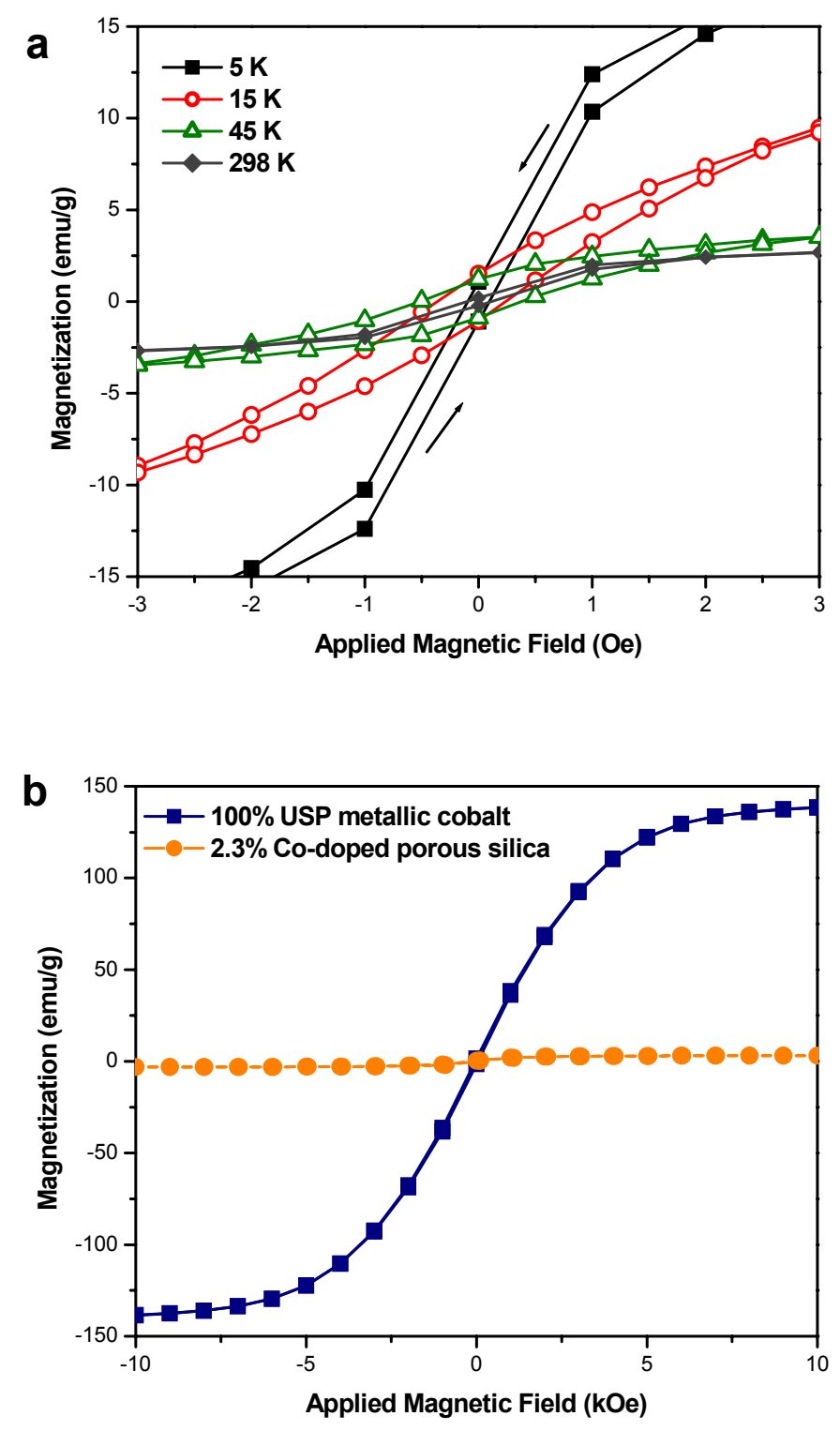

Supporting Information Figure 6. SQUID magnetization data for 1:10=silica:monomer sample (a) Magnetization vs magnetic field between $5 \mathrm{~K}$ and $298 \mathrm{~K}$. Hysteresis is observed. (b) Comparison data against $100 \%$ metallic cobalt prepared via USP at $298 \mathrm{~K}$. Magnetic susceptibility at saturation is approx. $143 \mathrm{emu} / \mathrm{g}$ for $100 \%$ metallic cobalt and $3 \mathrm{emu} / \mathrm{g}$ for 1:10 silica to monomer sample. The response is about $2 \%$ which corresponds well to EDS quantitative analysis data ( $2.3 \%$ Co-doping). 